\section{Respiratory Medicine}

\author{
Edited by Mark Woodhead BSc DM FRCP, \\ Consultant in General and Respiratory Medicine, \\ Department of Respiratory Medicine, Manchester Royal Infirmary
}

\section{Pleural effusions}

Stephen J Chapman MA MRCP, Wellcome Training Fellow, Wellcome Trust Centre for Human Genetics, Oxford University; Specialist Registrar, Oxford Centre for Respiratory Medicine, Osler Chest Unit, Churchill Hospital, Oxford

Robert JO Davies BM DM FRCP, Consultant, Oxford Pleural Diseases Unit, Oxford Centre for Respiratory Medicine, Osler Chest Unit, Churchill Hospital, Oxford

Clin Med 2004;4:207-10

This review describes the assessment and investigation of patients with pleural effusion, most of whom can be investigated and treated on an outpatient basis.

\section{History and examination}

Initial clinical assessment should be directed at identifying clues to the underlying cause of pleural effusion. Breathlessness is the commonest symptom and is non-specific. The presence of chest pain may be more helpful diagnostically; it implies a degree of pleural inflammation and is suggestive of an underlying exudative process such as malignancy, pleural infection or pulmonary infarction. Drugs are an occasional, often overlooked cause. ${ }^{1}$ Clinical assessment may reveal extrapulmonary features of an underlying malignancy or connective tissue disease. Mesothelioma is an increasingly common cause of pleural effusion, and a history of exposure to asbestos should be elicited and documented. Specific exposure may not be recalled by the patient, and it is advisable to elicit a complete occupational

Table 1. Pleural fluid analysis.

- Appearance

- Protein

- Lactate dehydrogenase

- $\mathrm{pH}$ stains and culture) haematocrit, triglycerides) history starting from employment on leaving school; high-risk occupations for asbestos exposure include work in construction, insulation, ship-building, electrical repair, carpentry and plumbing.

\section{Investigations}

Figure 1 shows a suggested algorithm for investigations leading to a diagnosis of pleural effusion.

\section{Chest radiography}

Pleural effusions become visible on postero-anterior chest radiograph (CXR) at volumes of around $200 \mathrm{ml}$. Lateral CXRs are more sensitive and can detect volumes as small as $50 \mathrm{ml}$. CXR may also identify parenchymal abnormalities, which may suggest an underlying cause for the effusion. Massive effusions are most commonly malignant in origin.

\section{Pleural fluid analysis}

Aspiration of pleural fluid for analysis (Table 1) is an important initial investigation. ${ }^{1}$ An exception is patients with a clinical diagnosis of left ventricular failure; it is reasonable to treat these patients initially with diuretics, reserving pleural aspiration for those with 'atypical' features (such as asymmetrical bilateral effusions, unilateral effusion, chest

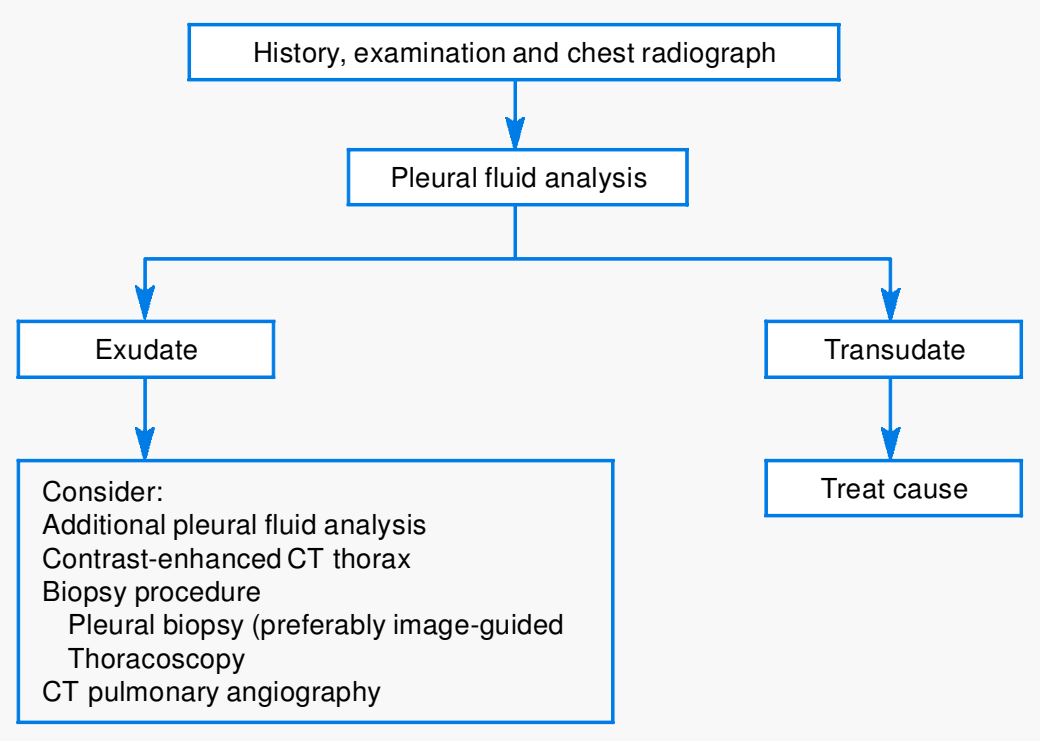

Fig 1. Diagnostic pathway for pleural effusion ( $C T=$ computed tomography).

- Microbiological analysis (Gram stain and culture, acid-fast bacilli

- Cytological analysis (differential cell count, malignant cells)

- Additional tests depending on clinical scenario (eg glucose, amylase, 
pain or fever) or whose effusions fail to respond to diuresis within several days. ${ }^{2}$

\section{Is the pleural fluid a transudate or an exudate?}

Causes of pleural effusion may be usefully divided into transudates and exudates on the basis of the protein concentration of pleural fluid (Table 2). Transudative effusions accumulate as a result of increased hydrostatic pressure or reduced osmotic pressure within the microvascular circulation and are characterised by a pleural fluid protein below $30 \mathrm{~g} / \mathrm{l}$. Exudates have a higher protein concentration $(>30 \mathrm{~g} / \mathrm{l})$ due to an increase in capillary permeability and/or impaired lymphatic drainage. Pleural fluid protein measurements should be interpreted in light of the serum protein. More stringent criteria are required (Light's criteria) in patients with an abnormal serum protein or pleural fluid

Table 2. Causes of pleural effusions.

\begin{tabular}{|c|c|}
\hline Pleural effusions & Causes \\
\hline Transudative & $\begin{array}{l}\text { - Left ventricular failure } \\
\text { - Cirrhotic liver disease } \\
\text { - Pulmonary embolism } \\
\text { (10-20\% are } \\
\text { transudates) } \\
\text { - Peritoneal dialysis } \\
\text { - Nephrotic syndrome } \\
\text { - Atelectasis } \\
\text { - Hypothyroidism } \\
\text { - Malignancy (5\% are } \\
\text { transudates) }\end{array}$ \\
\hline Exudative & $\begin{array}{l}\text { - Parapneumonic effusion } \\
\text { and empyema } \\
\text { - Malignancy } \\
\text { - Pulmonary embolism } \\
\text { - Mesothelioma } \\
\text { - Tuberculosis } \\
\text { - Rheumatoid arthritis, } \\
\text { systemic lupus } \\
\text { erythematosus and } \\
\text { other connective tissue } \\
\text { diseases } \\
\text { - Oesophageal rupture } \\
\text { - Pancreatitis } \\
\text { - Post-coronary artery } \\
\text { bypass surgery } \\
\text { - Drug-induced } \\
\text { - Chylothorax }\end{array}$ \\
\hline
\end{tabular}

protein levels close to $30 \mathrm{~g} / \mathrm{l}$ (Table 3$)^{2} .^{2}$ Applying Light's criteria to pleural fluid analysis is highly sensitive for the diagnosis of exudates, but may rarely misidentify a transudative effusion as an exudate, most commonly in heart failure partially treated with diuretics.

\section{Low $\mathrm{pH}$ effusions}

An abnormally low pleural fluid $\mathrm{pH}$ $(<7.3)$ may follow bacterial or tumour cell metabolism and is often accompanied by a reduced pleural fluid glucose $(<3.3 \mathrm{mmol} / \mathrm{l}$ or pleural fluid/serum glucose ratio <0.5). ${ }^{3}$ This combination is relatively specific for a limited number of exudates (Table 4).

\section{Additional pleural fluid analysis}

Further investigations may be considered in specific clinical circumstances. For example, a raised pleural fluid amylase

Table 3. Light's criteria for distinguishing transudates and exudates.

Pleural effusion is an exudate if it meets one or more of the following criteria:

- Pleural fluid protein to serum protein ratio $>0.5$

- Pleural fluid LDH to serum LDH ratio $>0.6$

- Pleural fluid LDH more than twothirds the upper limit of normal serum LDH

$\mathrm{LDH}=$ lactate dehydrogenase.

Table 4. Causes of low pH and low glucose pleural effusions.

- Complicated parapneumonic effusion and empyema

- Malignant pleural effusion

- Rheumatoid pleuritis

- Tuberculous pleural effusion

- Oesophageal rupture

- Lupus pleuritis concentration may occur with oesophageal rupture, although it may also be found in pleural malignancy and pancreatitis. Disruption to the thoracic duct (eg by trauma or lymphoma) may result in a chylothorax, sometimes with a characteristic 'milky' appearance to the pleural fluid. Pleural fluid triglyceride levels above $110 \mathrm{mg} / \mathrm{dl}$ confirm this diagnosis. ${ }^{1}$

\section{Contrast-enhanced thoracic computed tomography}

If pleural fluid analysis is non-diagnostic, the recommended investigation is contrast-enhanced thoracic computed tomography $(\mathrm{CT})$. Images taken prior to the complete removal of pleural fluid improve visualisation of the pleural surfaces and render later attempts at imageguided pleural biopsy safer. CT is most useful in distinguishing benign from malignant pleural thickening; it may also identify other unsuspected pulmonary lesions such as an endobronchial tumour.

\section{Pleural biopsy}

A pleural biopsy is often necessary for the diagnosis of exudative effusions. Techniques include ultrasound- or CTguided biopsy, blind (Abrams') biopsy or biopsy at thoracoscopy. Image-guided biopsy is the preferred biopsy technique for possible malignant disease as it has a greater diagnostic yield than blind (Abrams') biopsy. ${ }^{4}$ Abrams' biopsy is more sensitive for tuberculosis than for malignancy. Thoracoscopy allows direct visualisation of the pleural surfaces. Thoracoscopic biopsies have a sensitivity of $80-95 \%$ for malignancy and pleurodesis may be performed at the same time. This is therefore the 'gold standard' investigation. Bronchoscopy is unhelpful unless specific features suggest an underlying bronchial malignancy such as haemoptysis.

\section{Treatment}

Treatment of both transudative and exudative effusions should be directed at the underlying cause. Exudative effusions frequently also require removal of the pleural fluid for symptomatic relief. 
This can be achieved either by therapeutic aspiration of 1-2 litres of fluid or by insertion of an intercostal drain. Chest drain insertion is associated with significant morbidity, and even mortality, and is not always required.

\section{Specific causes of pleural effusion}

\section{Parapneumonic effusion and empyema}

Parapneumonic effusions complicate at least half of all pneumonias and are the commonest cause of an exudative effusion in young patients. Most such effusions are sterile and resolve with antibiotic treatment alone, but a small proportion become infected and require drainage procedures for resolution (complicated parapneumonic effusion and empyema) (Table 5). ${ }^{5}$

Pleural infection is a serious condition with a mortality approaching $20 \%$. It is often unsuspected and delays in diagnosis are common. The finding of a pleural effusion in the context of a pneumonic illness should prompt pleural fluid sampling. Empyema may also present more insidiously with non-specific symptoms such as weight loss, and the CXR opacity may be mistaken for malignancy.

The discovery of frankly purulent pleural fluid and/or the presence of organisms on pleural fluid Gram stain or culture is diagnostic of pleural infection

Table 5. Characteristics of parapneumonic effusions and empyema.
Simple parapneumonic effusion

Simple parapneumonic effusion

Complicated parapneumonic effusion

$\begin{array}{ll} & \text { appearance, } \mathrm{pH}<7.3 \text {, low glucose and raised } \\ & \text { - Pleural fluid Gram stain and/or culture may be } \\ & \text { positive } \\ \text { Empyema } & \text { - Drainage required for resolution } \\ & \text { - Pus in pleural space } \\ & \text { - Pleural fluid Gram stain and/or culture may be } \\ & \text { positive } \\ & \text { - Drainage required for resolution }\end{array}$

LDH = lactate dehydrogenase normal $\mathrm{pH}$, glucose and LDH

- Most resolve with antibiotic treatment alone

- Drainage not usually required

- Fluid infected but not purulent, clear or turbid appearance, $\mathrm{pH}<7.3$, low glucose and raised

Pleural fluid Gram stain and/or culture may be positive

- Pus in pleural space

positive

Drainage required for resolution and an indication for drainage of the effusion. A pleural fluid $\mathrm{pH}$ below 7.3 in the appropriate clinical setting is highly suggestive of pleural infection and an indication for intercostal tube drainage. Additional treatment of pleural infection comprises prolonged courses of antibiotics, including anaerobic cover, as well as nutritional support.

\section{Malignancy}

Malignancy is the commonest cause of exudative pleural effusions in patients over the age of 60 . Most cases represent metastatic disease, the commonest primary sites being lung, breast, lymphoma and the genitourinary and gastrointestinal tracts, but in about $10 \%$ of cases the primary site remains unknown. ${ }^{6}$ Pleural fluid cytological analysis has an overall sensitivity of $60 \%$ for the diagnosis of malignancy; if an initial sample is negative, the diagnostic yield may be further increased by analysis of a second, but not a third, sample. The finding of nodular, mediastinal or circumferential pleural thickening on CT is highly suggestive of malignant disease. Imageguided or thoracoscopic pleural biopsy is required in cytology-negative cases.

Management of symptomatic effusions consists of fluid drainage and consideration of pleurodesis. Malignant pleural disease has a generally poor prognosis, with a survival of 3-12 months from diagnosis.

\section{Mesothelioma}

Mesothelioma is a malignant tumour of the pleura or peritoneum usually resulting from asbestos exposure, ${ }^{7}$ sometimes following very low exposure. There is a lag time of 20-40 years between exposure and disease development. The incidence of mesothelioma is forecast to peak at around 2020 in the UK. ${ }^{8}$

Pleural fluid cytological analysis is relatively insensitive for mesothelioma, but may confirm an alternative diagnosis such as pleural adenocarcinoma. Mesothelioma has a tendency to invade needle and biopsy tracks in the chest wall, so the number of pleural procedures should be minimised by early consideration of investigations likely to be definitive such as image-guided or thora-

\section{Key Points}

\section{Distinguishing transudates from exudates is a helpful initial step in the investigation of pleural effusion}

Light's criteria are a robust method for distinguishing transudative effusions from exudates

Computed tomography of the chest should precede pleural biopsy in most cases of undiagnosed pleural effusion

\section{Thoracoscopy is the 'gold standard'} investigation

Pleural infection is often unsuspected it should be considered in cases of 'slow to resolve' pneumonia as well as less specific presentations such as weight loss in the absence of fever or chest symptoms

Parapneumonic effusions with a purulent appearance, organisms on Gram stain or culture, or pH below 7.3 are indications for intercostal drainage

Mesothelioma is increasingly common and should be considered even in the absence of an obvious history of asbestos exposure

KEY WORDS: empyema, exudate, malignant effusion, mesothelioma, pleural fluid analysis, thoracoscopy, transudate 


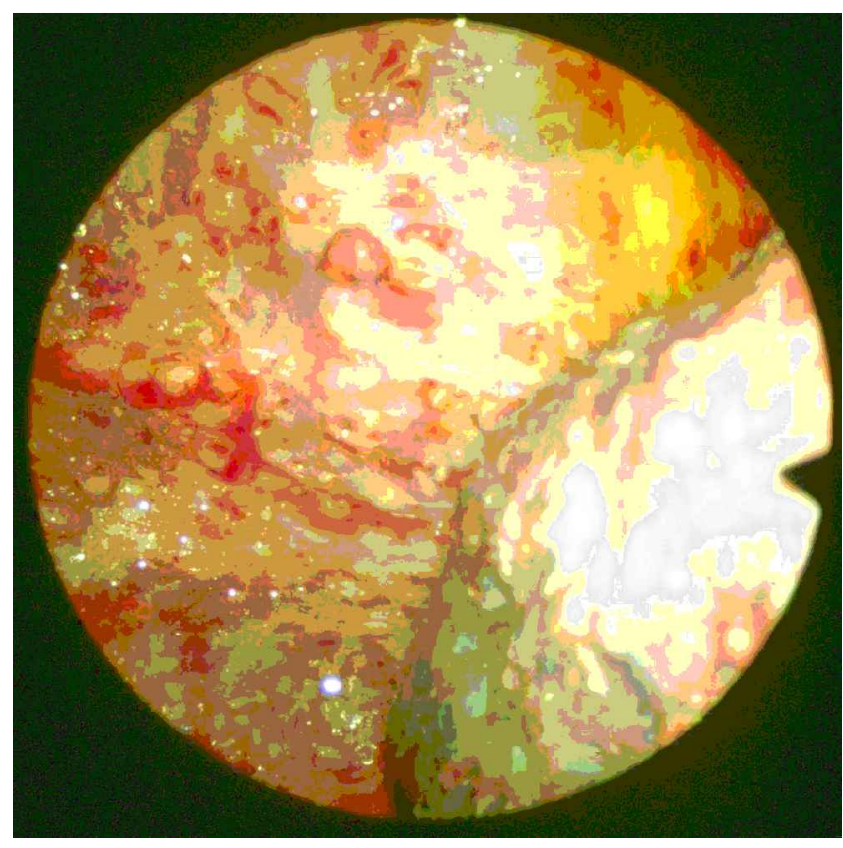

Fig 2. Thoracoscopic photograph of a malignant pleural mesothelioma with tough nodular white tumour tissue visible on the parietal pleura. The tumour has spread on to the visceral pleura (right) to produce a trapped lung incapable of reexpansion. coscopic biopsy (Fig 2). All pleural aspiration and biopsy sites should be marked with an ink 'tattoo' to guide prophylactic chest wall radiotherapy which is effective in preventing chest wall invasion.

Treatment of mesothelioma is supportive, including pleurodesis for symptomatic effusions. There is currently no evidence of benefit from surgery. Trials of chemotherapy are in progress. The prognosis in mesothelioma is poor, with median survival of 8-14 months.

\section{Pulmonary embolic disease}

Pulmonary embolic disease is a relatively common cause of pleural effusion. ${ }^{9}$ Analysis of the pleural fluid is nonspecific and effusions may be exudates or transudates. A high index of suspicion is required to make the diagnosis. Pulmonary emboli should be considered particularly if breathlessness is out of proportion to the size of effusion. The most useful investigation is CT pulmonary angiography.

\section{Tuberculosis}

Pleural fluid analysis typically reveals a lymphocytic exudate and pleural fluid culture has a low diagnostic sensitivity. The diagnosis is usually established following staining and culture of pleural biopsy tissue. Treatment is identical to that for pulmonary tuberculosis. The role of steroids in the treatment of tuberculous pleurisy remains uncertain. They may hasten both the resolution of symptoms and the absorption of pleural fluid, although this has not been confirmed in all studies. ${ }^{10}$

\section{Conflicts of interest}

None.

\section{References}

1 Maskell NA, Butland RJ; Pleural Diseases Group, Standards of Care Committee, British Thoracic Society. BTS guidelines for the investigation of a unilateral pleural effusion in adults. Thorax 2003;58(Suppl 2):ii8-17.

2 Light RW. Clinical practice. Pleural effusion. N Engl J Med 2002;346:1971-7.

3 Sahn SA. The diagnostic value of pleural fluid analysis. Sem Respir Crit Care Med 1995;16:269-78.

4 Maskell NA, Gleeson FV, Davies RJ. Standard pleural biopsy versus CT-guided cutting-needle biopsy for diagnosis of malignant disease in pleural effusions: a randomised controlled trial. Lancet 2003; 361:1326-30.

5 Davies CW, Gleeson FV, Davies RJ; Pleural Diseases Group, Standards of Care Committee, British Thoracic Society. BTS guidelines for the management of pleural infection. Thorax 2003;58(Suppl 2):ii18-28.

6 Antunes G, Neville E, Duffy J, Ali N; Pleural
Diseases Group, Standards of Care Committee, British Thoracic Society. BTS guidelines for the management of malignant pleural effusions. Thorax 2003; 58(Suppl 2):ii29-38.

7 British Thoracic Society Standards of Care Committee. Statement on malignant mesothelioma in the United Kingdom. Thorax 2001;56:250-65.

8 Peto J, Hodgson JT, Matthews FE, Jones JR et al. Continuing increase in mesothelioma mortality in Britain. Lancet 1995;345:535-9.

9 Light RW. Pleural effusion due to pulmonary emboli. Review. Curr Opin Pulm Med 2001;7:198-201.

10 Matchaba PT, Volmink J. Steroids for treating tuberculous pleurisy. Review. Cochrane Database Syst Rev 2000;No.2: CD001876. 